\title{
Effect of Implementing Total Parenteral Nutrition Nursing Guidelines on Adult Critically Ill Patients' Outcomes
}

\author{
Asmaa Aly Mahgoub $^{1,} \quad$ Naglaa Gamal Eldien AbdElhafez ${ }^{2}, \quad$ Enace Mohamed Abdelal ${ }^{3}$ \\ 1.lecture in critical Care and emergency Nursing, Assiut University \\ 2.lecture in critical Care and emergency Nursing, Sohag University \\ 3. lecture in Medical surgical Nursing, Sohag University
}

\begin{abstract}
Total parenteral nutrition for hospitalized critically ill patients is essential for improving outcomes, insufficient nutritional support lead to occurrences of complications, increased morbidity and mortality rates, increased length of hospital stay. Critical care nurses are the cornerstone in preventing theses complications. Aim: To investigate the effect of implementing total parenteral nutrition nursing guidelines on adult critically ill patients' outcomes. Design: Non randomized prospective research design was used to utilize this study Subjects: convenience samples of 60 patients were assigned equally to study and control group at intensive care units at Assiut University hospitals. The control group received routine hospital care during TPN administration while, the study group received the developed guidelines for TPN during a period from January 2018 to December 2018. Methods Each patient in both groups were assessed by taking history, clinical examination, nutritional assessment laboratory investigation. Patients in study groups were received care according to developed total parenteral nutrition guidelines to determine outcome and complications in both groups. Results Finding of the present study revealed that significant improvement in study group with values of less than $\mathrm{p}=001$ compared to control group Conclusion: implementing of total parenteral nutrition guidelines improve the outcomes and reduce the occurrence of complications among critically ill patients.
\end{abstract}

Keywords: total parenteral nutrition, nursing guidelines, critically ill patient, outcomes

DOI: $10.7176 / \mathrm{JHMN} / 61-04$

Publication date: April $30^{\text {th }} 2019$

\section{Introduction:-}

Total Parenteral Nutrition (TPN) is the special formula of nutrition administered via a peripherally inserted central catheter (PICC), or a central venous line (CVC). The benefits of parenteral nutrition in adult ICU improve immune system, reduction of complications and improve clinical outcomes (Ferreira, 2017). TPN includes macronutrients such as carbohydrates, amino acids, essential fatty a cids, and micronutrients as electrolytes, vitamins, minerals, trace elements, and other additives (Dudek, 2016) TPN is prescribed for various reasons and over varying periods of times. TPN support is indicated if there is intolerance to oral intake, and who have reversible loss of gastrointestinal(GI) function or enteral feeds. Short-term TPN (7 to 10 days) or long-term TPN (>10 days) is used to treat patients whose GI tract is not functioning or not accessible for various reasons and is administered continuously until enteral feeding can be re-established (Perry \& Potter ,2016)

Patients in acute setting have high rates of malnutrition and critical diseases are typically associated with a catabolic stress state. Inadequate or inappropriate nutritional support lead to increased mortality and morbidity rates, prolonged intubation, weakened respiratory muscles and failure of weaning from mechanical ventilation, increased length of ICU and hospital stay and infections that can lead to sepsis, multi organ failure, and even death ( Smith \& Young,2015).TPN administered to critically ill patients based on the patient's clinical history, laboratory data ,anthropemetric data as weight, height and arm skin folds, and current requirements including macro and micronutrients component administered intravenous under sterile technique. The infusion rate may be adjusted gradually to prevent electrolyte imbalance. The critical care nurse monitor amino acids/ dextrose solution is ordered, based on the patient's investigation and metabolic needs. Grenvick ,2014)

TPN formulas typically contain three fuel sources macronutrients: carbohydrates, lipids, and amino acids . When three fuel sources are combined together in one TPN bag, this is often referred to as a " 3 in 1" admixture. The desired proportions of these nutrients are prepared by a pharmacist under a laminar flow hood to maintain strict sterility.. Medications are not to be added to a TPN bag after it has been prepared by the pharmacist because of the risk of contamination or precipitation of its contents. (Sun ,2016) The current trend for TPN formulation is based on the specific needs of each patient; standard formulas are no longer widely prescribed. Vitamins, minerals, and trace elements are considered micronutrients. Trace elements also come in a variety of commercial mixtures but typically include chromium, copper, manganese, zinc, and selenium. Iron and iodine are not routinely added to TPN solutions and may need to be supplemented in long-term therapy. Most electrolyte mixtures contain sodium, chloride, potassium, magnesium calcium, and phosphorus. Depending on the patient's underlying disease process and physical assessment findings, specific electrolyte concentrations can be adjusted daily in the TPN solution. If an electrolyte deficiencyis detected after the TPN solution has already been prepared or while infusing, 
additional IV supplements can be given as a separate IV piggyback (Marino, 2014)

Complication associated with TPN can be categories into metabolic, infectious and mechanical complications. Many metabolic complications stem from the patient's diseases or from imprudent formula administration. The common metabolic complications include hyperglycemia, hypoglycemia, hypokalemia, hypophosphatemia and hypomagnesemia. (Perry \& Potter ,2016). Some metabolic disturbances can be prevented by checking each bag of parenteral nutrition solution for transcription accuracy for infusion and monitor the patient's response to therapy. Refeeding syndrome. This is characterized by rapid changes in electrolytes (phosphorus, potassium, magnesium, calcium), glucose, and volume status within hours to days of nutrition implementation. Prevention and management of refeeding syndrome include correction of pre-existing glucose and electrolyte abnormalities before institution of nutritional therapy. Total volume and rate are titrated slowly to evaluate for fluid overload and potential cardiac decompensation. Accurate intake and output measurements and daily weights are of paramount importance because adequate parenteral nutrition often means giving 1.5 to $3 \mathrm{~L}$ of fluid per day in addition to other therapies. If the patient has impaired cardiac or renal function, this could lead to fluid overload and congestive heart failure; a progressive weight gain could be an early indicator of poor fluid tolerance .( Gonce and Fontaine, 2018)

Infectious complications from both solution and indwelling catheter are prim sites for infection. The critical care nurse changes the TPN solution bag and tubing according to institution policy usually every 24 hours . Fortunately, transparent dressing allow for easier observation of the catheter entrance site, visible inflammation indicates significant bacterial colonization and the need for catheter removal . the nurse examines the site for signs of leakage, erythema and then cleanses the site with antibacterial solution to remove the pathogens. Chlorhexidine solution are effective local antiseptic,.Central venous catheter is a more leading source of nosocomial blood infection with an estimate 10\% mortality. Treatment of an infection may involve local topical antibiotics, systemic antibiotics and in many patients catheter removal if catheter sepsis suspected ,the catheter tip usually cultured to identify the offending microorganism and ensure the sensitive antibiotics. (Perry \& Potter ,2016)

Mechanical complications includes complications associated with central catheter inseration such as trauma to the vessel , pneumothorax, venous air embolism, catheter occlusion and thrombosis . After insertion of a central catheter, a chest radio graph is the standard of care to confirm correct placement. If there is a clinical suspicion of catheter tip migration or other potential complications, further diagnostic testing is indicated. Trauma to vessels and pneumothorax are complications that may warrant surgical intervention, insertion of a chest tube or tubes, or both. Catheter occlusion can simply be a result of the catheter tip lodging against the vessel wall or being physiologically "pinched" between the clavicle and first rib. Occlusion can also occur from fibrin buildup, blood or lipid deposition, drug precipitates, and catheter breakage. Another type of occlusion, "withdrawal occlusion," is an occlusion that allows infusion of a solution but prevents blood withdrawal . (Motor \& Fontaine,2016) .

Thrombosis formation in the lumen of the vessel often results from mechanical irritation, nurses need to be aware that patients may have a thrombosis and may be asymptomatic. Vigilant assessments during parenteral nutrition administration are recommended. Treatment includes catheter removal, systemic anticoagulation, and thrombolytic therapy. A venous air embolism is another serious complication, with a mortality rate of up to $50 \%$. Any disruption of the closed catheter system (usually during line connection changes, when hanging a new bag of TPN, or in an accidental tubing disconnection) can increase the risk for an air embolism. If such an incident occurs, the patient will most likely experience acute, centrally located chest pain, dyspnea, and hypotension. Immediate nursing interventions include clamping the tubing of the catheter or occluding the catheter hub, attempting to aspirate air directly from the venous line, administering $100 \%$ oxygen, and placing the patient in steep Trendelenburg's position with the left lateral side down (because this position allows air to rise to the level of the right ventricle, away from the pulmonary vasculature). Prevention of an air embolism can be facilitated by having the patient perform the Valsalva maneuver or simply hum audibly during line changes. In ventilator-dependent patients, positive intrathoracic pressure can be created by initiating mechanical lung inflations or "breaths." Finally, use of sterile occlusive dressings (e.g., petroleum gauze) over the catheter entrance site is an effective measure in preventing air from entering the track after the catheter has been discontinued. .( Gonce and Fontaine,2016)

2.Objective of the study: To investigate the effect of implementing total parenteral nutrition nursing guidelines on adult critically ill patients' outcomes

\section{Subjects and Methods}

Research Design: Non randomized prospective research design was used to utilize this study.

Subjects: A convenience sample of sixty patients of both adult sex were classified into two study and control groups and received TPN in ICUs at Assiut university hospital .Control group received at Assiut university hospital at Assiut university hospital routine hospital care during TPN administration While, the study group received the developed guidelines for TPN. Pregnant or lactating females were excluded from the study. 
3.1.Tools:Three tools were used to achieve the aim of the study.

Tool I: Patient Assessment Sheet. This tool was developed by the researcher after reviewing the related literature. $(1,3,5,7)$ It includes the 4 parts:

Part 1: - Assessment of the Patients profile, as patient's code, age, sex, diagnosis, date of admission

Part 2:-Modified physical assessment sheet:it includes respiratory system assessment, hemodynamic parameters, mechanical ventilated parameters to assess patient condition.

Part 3: laboratory investigation findings includes renal, hepatic function tests and electrolytes to evaluate the patient

Tool II: - Nutritional assessment sheet: This includes dietary data and fluid intake and output and anthropometric data (Height, weight, triceps skin fold thickness and mid-upper-arm circumference)

Tool III: Patient's outcomes sheet: this tool includes mortality rate, duration of ICU stay and occurrence of complications related to TPN

3.2 Methods: Permission was obtained from the responsible administrative personnel at intensive care units. Content validity: It was established by panel of 5 experts' professors in fields of medicine and nursing who reviewed the instruments for clarity, relevance, comprehensiveness, understanding, applicability and easiness for administrative minor modifications were required. The content validity of this tool was checked by expert. Reliability was established by $10 \%$ of the total study subjects to test the tools. Analyses of the pilot study revealed that minimal modifications are required. These modifications were done and the subjects were not excluded from the actual study.

Ethical considerations: -proposal confirmed from ethical committee., no hazard for study subject during application of the research. Written consent was obtained from patients or relatives.

Data collection: Data were collected over 1-year period extending from January 2018 to December 2018 in ICUs from started TPN until seven days .The study conducted on four phases "assessment phase, development phase, implementing phase and evaluation phase".

Phase I: Assessment Phase for the control group: During this phase the researcher assess patient's profile data, then assess respiratory system, hemodynamic parameters, mechanical ventilated parameters to assess patient condition, and assessment of laboratory investigation findings and nutritional assessment by using tool one - The researcher introduced herself for the patients, patient's family and nursing staff and explained the purpose of the study. The patients profile was collected from the patient or from nurses if the patient was comatose, and recorded in part I tool I

- Assessment of nutritional was done when initiation of nutritional support and subsequently on $7^{\text {th }}$ day includes anthropometric measurement's as height measured with the patient in the supine position,weight measured by Ross Laboratories equation :Body weight $(\mathrm{kg})=($ knee height $\mathrm{x} 1)+(\operatorname{arm}$ circumference $\mathrm{x} 2.81)$

-Measurement of skin-fold thickness by A skinfold caliper at the mid-point of the non-dominant arm (between the acromial process and the olecranon) with the arm freely stretched along the body. A fold of skin was then pinched with the fingers and a scientific caliper (Cescorf Scientific, Cescorf, Brazil) was applied

-Assessment of mid-upper-arm circumference by measuring Tap it measured at the mid-point between the tip of the shoulder and the tip of the elbow

-Laboratory investigation such as protein status electrolyte disturbance and kidney functions, blood glucose taken on admission then Every 3 day.

-Monitor the patients' heart rate, blood pressure and temperature daily

-Assessment of patient outcomes as length of hospital stay, weight loss , positive nitrogen balance, respiratory system assessment, serum electrolytes disturbance, number of days on mechanical ventilator

-Evaluate patient by signs of infection, fluid and electrolyte imbalance and nutritional status while receiving TPN -Monitor intake and output

-Both group assessed by tool I

Evaluation of clinical outcomes for patients in the control group:

Data for this group were collected from 30 patients who met the predetermine criteria in the control group who received the routine unit care. The patient's assessed for respiratory system complication ( wheezing, dyspnea, orthopnea, cough , sputum, hemoptysis , crackles and using oxygen mask Tracheostomy and endotracheal tube ) using tool I part II

- Hemodynamic parameters assessment such as ( heart rate, blood pressure, temperature, CVP readings , oxygen saturation ) using tool I part I

- $\quad$ Mechanical ventilated parameters assessment (Vt , PEEP , FIO2, RR, Type of mod used ) using tool I part II

- laboratory tests findings includes ( compete blood count, blood urea, total protein, serum urea, blood sugar, sodium ,magnesium ). using tool I part II

- Nutritional assessment This includes dietary and fluid intake history, anthropometric (Height, weight , 
skin fold thickness and mid-upper-arm circumference, skin turgor) using tool II .

- $\quad$ assessment of outcomes ( mortality number, duration of stay on in ICU, weight loss, serum protein decrease, positive nitrogen balance, number of days on mechanical ventilator)

- assessment of occurrences of complications related to administration of TPN ( hyperglycemia , hypoglycemia , hyponatremia, hypokalemia ,hypomagnesaemia . using tool three (III)

Phase II: Developing phase for TPN nursing guidelines :This guidelines was developed by the researcher after reviewing the related literatures and accomplished by the following steps_ $\left.{ }_{-}{ }^{6}, 66,67-68-69-70-71-72-73-74-75\right)$

- Determination of the need and scope of guidelines:

The need was gathered by the researcher through the reflection of the current nursing practice obtained during assessment phase which identified nursing needs and the available resources to implement guidelines, Moreover, during this step the researcher accurately defined the target population, health setting and areas of care being considered which included the following;

The target population involved critically ill patients who receiving total parenteral nutrition in intensive Care Unit at Assiut University hospitals.

- The Health care setting involve General and trauma

-Guideline objectives: To investigate the effect of implementing total parenteral nutrition nursing guidelines on adult critically ill patients' outcomes

- Establishment of a multidisciplinary guidelines development group:

In addition to the researcher, three academic experts in critical care nursing and medicine , the guidelines development were convened to review the process of guidelines development

Identification of outcomes:

- Specific outcomes measured included outcomes ( mortality rate, duration of stay on in ICU, weight loss , serum protein decrease , positive nitrogen balance, number of days on mechanical ventilator) and occurrences of complications related to administration of TPN (hyperglycemia, hypoglycemia , hyponatremia , hypokalemia ,hypomagnesaemia) for respiratory system complication ( wheezing , Dyspnea , orthopnea , cough , sputum, hemoptysis , crackles and using oxygen mask tracheostomy and endotracheal tube )

-Once the scope had been defined, the next stage for the researcher was to formulate the structured clinical questions which helped the researcher to identify the evidence needed from the subsequent systematic review. The formulated research hypothesis:

- A significant difference between study \& control group regarding occurrence of complications

- A significant difference between study \& control groups regarding outcomes

The researcher and ICUs administrators formulated TPN team:

To be responsible for application of TPN guidelines. This team consisted of the researcher, the responsible physician and the responsible nurses who were trained on the application of TPN guidelines

PhaseIII: Implementation phase :During this phase, the developed TPN guidelines were implemented for the intervention group which consisted of 30 patients who met the predetermined criteria, the following steps were followed during its implementation

-This phase was begun from first day of admission for $7^{\text {th }}$ day consequent days and every shift.

-During this phase the patients received the developed nursing guidelines.

- This guidlines were performed by the researcher with assistance of critical care nurses that involved in the providing direct patient's care.

- The following steps were followed during the implementation phase

1) Guidelines for Storage TPN : Bags of TPN stored in the refrigerator. Each bag must be removed from the refrigerator at least 1 -2hours before infusion .

2) Guideline for TPN administration :starting at no more than 50\% of estimated amount for the first 24-48hrs using a volumetric pump fitted with occlusion and air-in-line alarms to reduce the risk of embolus in the line .Check each TPN bag prior to administration to ensure there are no leaks in the bag. If a leak is present bag must not be used as the risk of microbial contamination is high. TPN bags must be covered by a light protective bag during infusion to reduce vitamin degradation ..All TPN bags must be discarded 24 hours after the infusion has commenced and a new TPN bag started even if solution remains in the bag. The researcher assessing the patient requirements for energy, macronutrients, micronutrients and electrolytes. which determined by physicians

3) Rate of administration: flow rate of TPN Start with $60-80 \mathrm{ml}$ hour and increase the rate slowly to avoid hyperglycemia. Never stop the IV solution abruptly and If feed is stopped the lumen must be flushed immediately .Draw back and flush for central lines to decrease the risk of occlusion.

4) Giving medication: Do not draw blood or . give medication or check central venous pressure Via TPN line . The line must be labelled. Do not disconnect TPN to give medication.

5) Guidelines for connecting a total parenteral nutrion infusion :equipment:- includes_total_parenteral nutrition 
bags and patient prescription chart ,Sterile gloves Sterile giving set - Needle-free connector , $10 \mathrm{ml} 0.9 \%$ sodium chloride for injection, $70 \%$ alcohol or alcohol/ chlorhexidine wipes .

Procedure :Hand washing and apply disposal gloves ,clean the central venous vascular access port with the $1 \%$ chlorhexidine and $70 \%$ isopropyl alcohol swab and allow to air dry.,flush lumen before starting with $20 \mathrm{mls}$ of sterile normal saline ,connect the TPN line to the dedicated central venous port and secure connection., check the prescribed rate is usually $20 \mathrm{~mL}$ per hour, increasing by approximately $20 \mathrm{~mL} /$ hour every $1-2$ hours up to a maximum rate of $80 \mathrm{~mL}$ per hour.,monitor the blood glucose every 6 hours during rate changes. Once stable monitor once daily.,monitor intake and output to maintain an accurate fluid balance,monitoring electrolytes and management of results. Remove gloves and Perform hand hygiene and document the TPN volumes infused on the fluid balance chart.

6) Central venous accesses dressings: A semi-permeable, transparent dressing should be used at all times, catheter dressings must be changed using sterile technique daily for the first week then every 48 hours or as required in cases as (blood present under the dressing, loose dressing ,catheter insertion site should be observed and documented each shift for Signs of redness, inflammation, ooze, chlorhexidine $2 \%$ in alcohol $(70 \%)$ solution should be used to clean the insertion site. If the patient is allergic to chlorhexidine, Povidone iodine $10 \%$ in alcohol (70\%) may be used. Allow to dry prior to dressing application and date the central dressing and document site condition in the patient's clinical notes.

7) Terminating TPN: Follow the rate reduction protocol as physicians' order, document the rate change on the fluid balance chart and integrated progress notes.TPN infusion rate decreased by $50 \%$ for $1-2$ hours before ceasing. If the patient is requiring insulin, the greater care needs to be taken when ceasing TPN

- If the TPN infusion is ceased suddenly a glucose infusion should be established and maintained for at least 12 hours after the insulin infusion is discontinued once the TPN is stopped flush the port with $10 \mathrm{~mL}$ $0.9 \%$ sodium chloride. Ports may then be used for other infusions.

\section{Guidelines for TPN complications}

冈 Assess complication related to carbohydrate administration includes signs of hypo/or hyperglycemia ,assess for manifestation of electrolytes imbalances as hypokalemia, hyponatremia , hypocalcaemia , hypomagnesaemia such as changes in the level of consciousness, confusion and lethargy; nausea, vomiting, muscle weakness, tremors, cramping, dysrhythmias , Paresthesia, tetany, seizures,

冈 Assess to fat emulsions complications as signs and symptoms of essential fatty acid deficiency as dry, scaly skin, easily bruised and thrombocytopenia, Poor wound healing, monitor serum triglyceride levels and assess for signs and symptoms of fat embolism (headache, cyanosis, skin flushing, and dyspnea) which is rare but serious complication of the infusion.

冈 Assess complication related to amino acids administration. Check signs of over hydration including coughing, dyspnea, neck vein engorgement, crackles and measure intake and output volume deficit or excess

囚 The researcher and assistant team monitor patients for electrolytes imbalance as hypokalemia, hypophosphatemia and hypomagnesemia to avoid refeeding syndrome

$\otimes$ Regular measures for trace elements and vitamins to evaluate excess or deficit of this elements.

\section{Phase VI: Evaluation phase:}

$\checkmark \quad$ This phase was done to evaluate the effect of implementing nursing guidelines for patient receiving TPN on outcomes, this was done by comparing the results of outcomes of the both groups regarding mortality number, duration of stay on in ICU, electrolytes disturbances and systemic complications using tool III.

$\checkmark$ Statistical analysis: Data were collected, analyzed by Statistical Package for Social Science (SPSS version 19. Data were presented using descriptive statistics in the form of frequencies and percentages for qualitative variables, and means and standard deviations for qualitative variables. Independent " $\mathrm{t}$ " test, analysis of variance (ANOVA) and Chi-square were used for comparisons between group's data. A pvalue $<0.05$ is significant and $p$-value $<0.001$ is highly significant 
4.Results \& data analysis

Table (1):- Distribution of study and control group regarding to demographic \& clinical data $(\mathrm{n}=60)$.

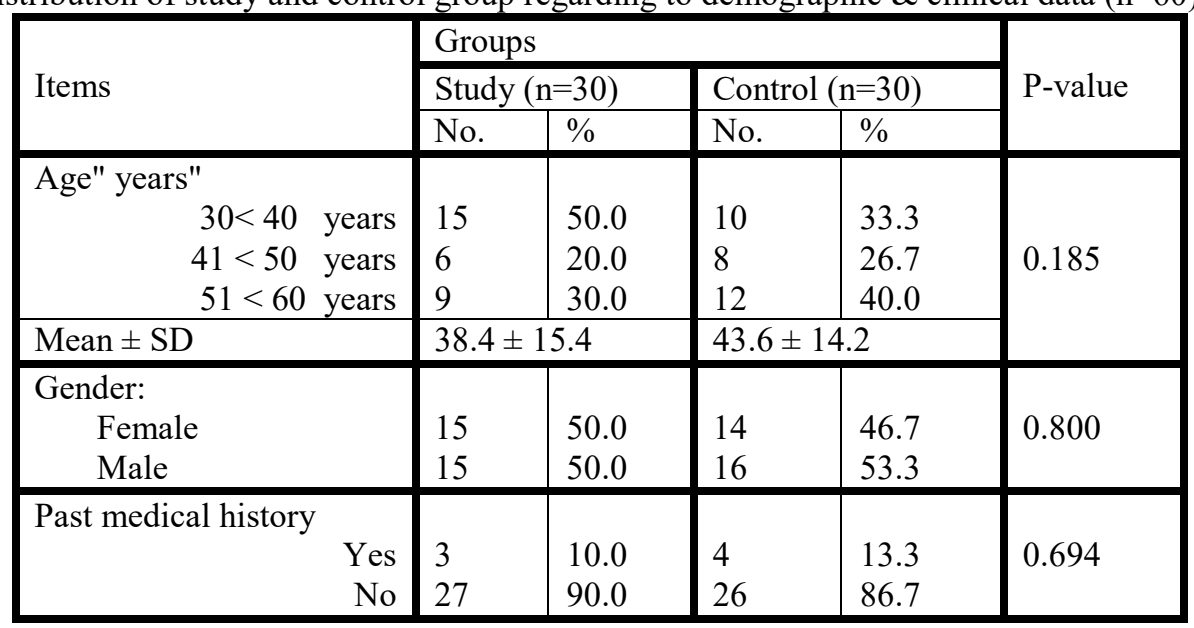

Chi- square test \& Independent samples t-test

$* \mathrm{P}<0.05$ significant

Table (1):-Shows that the highest percentage in study group age ranged from $(31<40$ years), while control group age ranged from $(51<60$ years $)$.Regarding to gender the highest percentage of control group were females $(53.3 \%)$, while the sample is equally distributed for study group $(50.0 \%)$ males and females , the vast majority $(90.0 \%, 86.7 \%)$ reported no past history for both group respectively,..No significant statistical difference was put in to evidence between the two groups in relation to socio demographic \& clinical data $\mathrm{p}>0.05$.

Table 2 : Mean and stander deviation of daily calories and proteins requirements of both study and control group.

\begin{tabular}{|c|c|c|c|c|c|}
\hline \multirow{3}{*}{ Items } & \multicolumn{4}{|c|}{ Groups } & \multirow{4}{*}{$\begin{array}{l}\text { P-value } \\
0.941\end{array}$} \\
\hline & \multicolumn{2}{|c|}{ Study $(n=30)$} & \multicolumn{2}{|c|}{ Control $(n=30)$} & \\
\hline & No. & $\%$ & No. & $\%$ & \\
\hline $\begin{array}{l}\text { Daily Caloric Req. } \\
\text { Mean } \pm \text { SD }\end{array}$ & \multicolumn{2}{|c|}{$1833.6 \pm 193.76$} & \multicolumn{2}{|c|}{$1893.6 \pm 207.48$} & \\
\hline $\begin{array}{l}\text { Daily Protein Req. } \\
\text { Mean } \pm \text { SD }\end{array}$ & \multicolumn{2}{|c|}{$122.97 \pm 12.77$} & \multicolumn{2}{|c|}{$119.94 \pm 13.25$} & 0.891 \\
\hline
\end{tabular}

Chi- square test $\&$ Independent samples t-test $\quad * \mathrm{P}<0.05$ significant

Table 2 :- Illustrated that no significant statistical difference on the daily caloric and protein requirements among the studied patients

Table (3): percentage distribution of study and control group in relation to patients' respiratory system assessment:

\begin{tabular}{|c|c|c|c|c|c|c|c|c|c|c|c|c|c|}
\hline \multirow{4}{*}{ Items } & \multicolumn{12}{|c|}{ Groups } & \multirow{4}{*}{$\begin{array}{l}\mathrm{P}- \\
\text { value }\end{array}$} \\
\hline & \multicolumn{6}{|c|}{ Study $(n=30)$} & \multicolumn{6}{|c|}{ Control $(n=30)$} & \\
\hline & \multicolumn{2}{|c|}{$1^{\text {st }}$ day } & \multicolumn{2}{|c|}{$3^{\text {rd }}$ day } & \multicolumn{2}{|c|}{$7^{\text {th }}$ day } & \multicolumn{2}{|c|}{$1^{\text {st }}$ day } & \multicolumn{2}{|c|}{$3^{\text {rd }}$ day } & \multicolumn{2}{|c|}{$7^{\text {th }}$ day } & \\
\hline & No. & $\%$ & No. & $\%$ & No. & $\%$ & No. & $\%$ & No. & $\%$ & No. & $\%$ & \\
\hline Normal & 12 & 40 & 15 & 50 & 24 & 80 & 15 & 50 & 10 & 33.3 & 11 & 36.7 & $0.001 *$ \\
\hline Wheezing & 15 & 50 & 12 & 40 & 9 & 30 & 9 & 30 & 13 & 43.3 & 16 & 53.3 & 0.309 \\
\hline Dyspnea & 9 & 30 & 6 & 20 & 5 & 16.7 & 6 & 20 & 5 & 16.7 & 11 & 36.7 & $0.01 *$ \\
\hline Orthopnea & 3 & 10 & 4 & 13.3 & 3 & 10 & 4 & 13.3 & 5 & 16.7 & 9 & 30 & 0.694 \\
\hline Coughing & 9 & 30 & 12 & 40 & 6 & 20 & 13 & 43.3 & 12 & 40 & 12 & 40 & $0.01 *$ \\
\hline Sputum & 3 & 10 & 6 & 20 & 3 & 10 & 6 & 20 & 7 & 23.3 & 9 & 30 & $0.009^{*}$ \\
\hline Hemoptysis & 2 & 6.7 & 3 & 10 & 2 & 6.7 & 6 & 20 & 2 & 6.7 & 9 & 30 & $0.01 *$ \\
\hline Crackle & 3 & 10 & 1 & 3.3 & 1 & 3.3 & 6 & 20 & 3 & 10 & 9 & 30 & $0.045^{*}$ \\
\hline Use of oxygen mask & 12 & 40 & 8 & 26.7 & 6 & 20 & 12 & 40 & 9 & 30 & 16 & 53.3 & $0.01 *$ \\
\hline $\begin{array}{l}\text { Incubated ETT or } \\
\text { tracheostomy }\end{array}$ & 15 & 50 & 9 & 30 & 9 & 30 & 16 & 53.3 & 12 & 40 & 15 & 50 & 0.425 \\
\hline
\end{tabular}

Independent samples t-test $\quad * \mathrm{P}<0.05$ significant $\quad$ ETT endotracheal tube

Table (3): This table showed characteristics of both study and control group in relation to patients' respiratory system assessment. There were a statistical significant difference at the $7^{\text {th }}$ day compared to the $1^{\text {st }}$ and $3^{\text {rd }}$ day of study group versus control group in relation to Dyspnea, Coughing, Hemoptysis, Crackle and Use of oxygen mask $\mathrm{P}<0.05$. While moderate statistical significant difference for normal breath and sputum production $\mathrm{P}<0.01$ 
Table (4):-Comparison between the studied groups in relation to Mechanical ventilator parameters mean values all through the assessment in both groups $(\mathrm{n}=60)$

\begin{tabular}{|c|c|c|c|c|c|c|c|c|c|c|c|c|c|}
\hline \multirow{3}{*}{ Items } & \multicolumn{12}{|c|}{ Groups } & $\begin{array}{l}\mathrm{P}- \\
\text { value }\end{array}$ \\
\hline & \multicolumn{6}{|c|}{ Study $(n=30)$} & \multicolumn{6}{|c|}{ Control $(n=30)$} & \\
\hline & \multicolumn{2}{|c|}{$1^{\text {st }}$ day } & \multicolumn{2}{|c|}{$3^{\text {rd }}$ day } & \multicolumn{2}{|c|}{$7^{\text {th }}$ day } & \multicolumn{2}{|c|}{$1^{\text {st }}$ day } & \multicolumn{2}{|c|}{$3^{\text {rd }}$ day } & \multicolumn{2}{|c|}{$7^{\text {th }}$ day } & \\
\hline $\begin{array}{l}\mathrm{VT} \\
(\mathrm{ml} / \mathrm{min})\end{array}$ & \multicolumn{2}{|c|}{$537.6 \pm 160.6$} & \multicolumn{2}{|c|}{$493.6 \pm 115.8$} & \multicolumn{2}{|c|}{$448.1 \pm 62.7$} & \multicolumn{2}{|c|}{$523.2 \pm 109.0$} & \multicolumn{2}{|c|}{$478.3 \pm 67.2$} & \multicolumn{2}{|c|}{$426.2 \pm 71.3$} & 0.787 \\
\hline PEEP & \multicolumn{2}{|c|}{$7.0 \pm 0.9$} & \multicolumn{2}{|c|}{$6.1 \pm 1.0$} & \multicolumn{2}{|c|}{$5.8 \pm 1.2$} & \multicolumn{2}{|c|}{$6.7 \pm 1.4$} & \multicolumn{2}{|c|}{$7.9 \pm 1.2$} & \multicolumn{2}{|c|}{$7.0 \pm 2.9$} & $0.005 *$ \\
\hline FIO2 & \multicolumn{2}{|c|}{$39.0 \pm 11.5$} & \multicolumn{2}{|c|}{$36.9 \pm 6.0$} & \multicolumn{2}{|c|}{$35.6 \pm 4.0$} & \multicolumn{2}{|c|}{$40.0 \pm 10.7$} & \multicolumn{2}{|c|}{$39.8 \pm 5.3$} & \multicolumn{2}{|c|}{$47.1 \pm 24.5$} & $0.001 *$ \\
\hline $\mathrm{RR} / \mathrm{b} / \mathrm{min}$ & \multicolumn{2}{|c|}{$13.6 \pm 1.0$} & \multicolumn{2}{|c|}{$13.6 \pm 1.0$} & \multicolumn{2}{|c|}{$12.2 \pm 1.5$} & \multicolumn{2}{|c|}{$13.6 \pm 1.0$} & \multicolumn{2}{|c|}{$14.3 \pm 3.9$} & \multicolumn{2}{|c|}{$16.5 \pm 8.0$} & $0.022 *$ \\
\hline Mode: & No & $\%$ & No & $\%$ & No & $\%$ & No & $\%$ & No & $\%$ & No & $\%$ & \\
\hline No & 12 & 40 & 15 & 50 & 18 & 60 & 11 & 36.7 & 11 & 36.7 & 10 & 33.3 & \\
\hline SIMV & 6 & 20 & 6 & 20 & 3 & 10 & 1 & 3.3 & 4 & 13.3 & 1 & 3.3 & \\
\hline CPAP & 3 & 10 & 0 & 0 & 3 & 10 & 6 & 20 & 0 & 0 & 1 & 3.3 & $0.042^{*}$ \\
\hline Bi level & 9 & 30 & 6 & 20 & 3 & 10 & 9 & 30 & 8 & 26.7 & 14 & 46.8 & \\
\hline PCV-VG & 0 & 0 & 3 & 10 & 3 & 10 & 3 & 10 & 7 & 23.3 & 4 & 13.3 & \\
\hline
\end{tabular}

Chi-square test $\quad * \mathrm{P}<0.05$ significant $\mathrm{Vt}$ :-Tidal volume PEEP:-Positive end expiratory pressure RR :Respiratory rate $\mathrm{FIO}_{2}$ :-Fraction of inspired oxygen SIMV:- Synchronized intermittent mandatory ventilation PCV-VG :- pressure control ventilation volume guaranteed CPAP :- Continuous positive airway pressure

Table (4) Clarifies that mechanical ventilator parameter's values show a significant statistical difference ( $p=0.05$ to 0.01 ) founded between the two groups in relation to mean (Respiratory rate) of study group subjects which improved than the base line readings as compared to the control group subjects who showed increased in respiratory rate, in the $7^{\text {th }}$ day . However no significant difference was founded between both groups in relation to tidal volume. While fio 2 shows slight tendency to be higher among control group compared to study group \& there were a statically significant difference ( $\mathrm{p}=0.05$ to 0.01 ). Concerning to PEEP level, showed nearly normal between the two groups but slight increased in the $7^{\text {th }}$ day among control group. Concerning to mode of mechanical ventilation it was founded that $60 \%$ of the study group not connected to MV in the 7 th day compared to $33.3 \%$ among control group

Table (5): Comparison between the studied groups in relation to laboratory investigation $(n=60)$.-

\begin{tabular}{|c|c|c|c|c|c|c|c|}
\hline \multirow{4}{*}{ Items } & \multicolumn{6}{|l|}{ Groups } & \multirow{4}{*}{$\begin{array}{l}\mathrm{P}- \\
\text { value }\end{array}$} \\
\hline & \multicolumn{3}{|l|}{ Study $(\mathrm{n}=30)$} & \multicolumn{3}{|c|}{ Control $(n=30)$} & \\
\hline & $1^{\text {st }}$ day & $3^{\text {rd }}$ day & $7^{\text {th }}$ day & $1^{\text {st }}$ day & $3^{\text {rd }}$ day & $7^{\text {th }}$ day & \\
\hline & Mean \pm SD & Mean \pm SD & Mean \pm SD & Mean \pm SD & Mean \pm SD & Mean \pm SD & \\
\hline WBC & $14.5 \pm 5.0$ & $12.2 \pm 0.5$ & $11.2 \pm 5.9$ & $11.6 \pm 4.4$ & $13.4 \pm 6.6$ & $18.0 \pm 1.3$ & $0.026^{*}$ \\
\hline Red blood cells & $3.0 \pm 0.0$ & $2.0 \pm 18.6$ & $4.7 \pm 0.3$ & $4.0 \pm 0.0$ & $4.4 \pm 1.4$ & $11.0 \pm 1.3$ & $0.038^{*}$ \\
\hline Hemoglobin & $8.6 \pm 2.1$ & $10.9 \pm 2.2$ & $13.2 \pm 1.2$ & $9.2 \pm 3.2$ & $10.54 \pm 2.3$ & $8.8 \pm 2.2$ & $0.001 *$ \\
\hline Hematocrit & $30.4 \pm 5.8$ & $25.6 \pm 8.0$ & $25.1 \pm 6.0$ & $32.5 \pm 9.3$ & $33.11 \pm 11.3$ & $36.4 \pm 10.4$ & $0.036^{*}$ \\
\hline Platelets & $217.0 \pm 125.5$ & $239.0 \pm 112.7$ & $251.5 \pm 107.8$ & $224.7 \pm 99.3$ & $196.5 \pm 110.8$ & $200.2 \pm 99.0$ & 0.385 \\
\hline $\begin{array}{l}\text { Blood urea } \\
\text { nitrogen }\end{array}$ & $12.9 \pm 11.2$ & $18.2 \pm 21.1$ & $12.4 \pm 9.3$ & $20.3 \pm 18.5$ & $23.3 \pm 16.8$ & $26.6 \pm 11.7$ & $0.049 *$ \\
\hline Serum creatinine & $169.8 \pm 141.1$ & $160.1 \pm 145.2$ & $138.1 \pm 121.6$ & $159.0 \pm 161.7$ & $144.1 \pm 124.0$ & $132.7 \pm 101.4$ & 0.784 \\
\hline Total bilirubin & $12.7 \pm 20.5$ & $11.7 \pm 20.4$ & $9.1 \pm 20.7$ & $11.8 \pm 15.0$ & $12.6 \pm 16.9$ & $10.6 \pm 17.9$ & 0.86 \\
\hline Total protein & $24.2 \pm 25.5$ & $22.7 \pm 21.8$ & $28.3 \pm 25.7$ & $30.1 \pm 23.0$ & $29.6 \pm 21.5$ & $29.6 \pm 20.6$ & 0.439 \\
\hline Albumin & $9.1 \pm 2.8$ & $7.6 \pm 2.5$ & $5.7 \pm 2.6$ & $11.1 \pm 2.9$ & $12.2 \pm 2.8$ & $8.7 \pm 2.9$ & 0.539 \\
\hline Serum sodium & $138.1 \pm 5.9$ & $140.5 \pm 3.6$ & $137.9 \pm 4.4$ & $136.7 \pm 5.0$ & $137.3 \pm 5.9$ & $122.5 \pm 6.5$ & $0.019^{*}$ \\
\hline Serum potassium & $4.2 \pm 0.8$ & $3.7 \pm 1.6$ & $3.9 \pm 1.0$ & $3.9 \pm 0.9$ & $3.7 \pm 1.2$ & $1.8 \pm 0.7$ & $0.01 *$ \\
\hline Serum urea & $8.8 \pm 4.6$ & $10.8 \pm 5.6$ & $12.8 \pm 6.2$ & $17.3 \pm 18.9$ & $17.9 \pm 16.6$ & $11.0 \pm 14.0$ & $0.073^{*}$ \\
\hline Blood sugar & $180.3 \pm 3.7$ & $117.9 \pm 2.6$ & $114.7 \pm 12.6$ & $127.9 \pm 2.8$ & $155.6 \pm 3.8$ & $260.25 \pm 13.65$ & $0.001^{*}$ \\
\hline Magnesium & $2.2 \pm 0.5$ & $2.1 \pm 0.4$ & $2.2 \pm 0.4$ & $1.9 \pm 0.8$ & $1.8 \pm 0.4$ & $1 \pm 0.3$ & $0.046^{*}$ \\
\hline
\end{tabular}

Chi-square test $\mathrm{P}>0.05$ non-significant $\quad * \mathrm{P}<0.05$ significant

Table (5) highlights that there significantly difference regard to the mean values of WBC, red blood cells, Hematocrit and blood urea nitrogen $<0.05$ While there were moderate statistical difference for hemoglobin concentration $<0.01$ founded by the end of the study between 2 groups . Regarding to kidney function it showed that statistical difference in the $7^{\text {th }}$ day in most of parameters in study group except blood sugar level which decreased in $7^{\text {th }}$ day compared to $1^{\text {st }} \& 3^{\text {rd }}$ day while in control group it show abnormal decrease in serum sodium, potassium, Magnesium and also show abnormal increases in serum blood urea nitrogen, blood sugar 
Table (6): patients' nutritional assessment of study and control group:

\begin{tabular}{|c|c|c|c|c|c|c|c|c|c|c|c|c|c|}
\hline \multirow{3}{*}{ Items } & \multicolumn{12}{|c|}{ Groups } & $\begin{array}{l}\mathrm{P}- \\
\text { value }\end{array}$ \\
\hline & \multicolumn{6}{|c|}{ Study $(n=30)$} & \multicolumn{6}{|c|}{ Control $(n=30)$} & \\
\hline & \multicolumn{2}{|c|}{$1^{\text {st }}$ day } & \multicolumn{2}{|c|}{$3^{\text {rd }}$ day } & \multicolumn{2}{|c|}{$7^{\text {th }}$ day } & \multicolumn{2}{|c|}{$1^{\text {st }}$ day } & \multicolumn{2}{|c|}{$3^{\text {rd }}$ day } & \multicolumn{2}{|c|}{$7^{\text {th }}$ day } & \\
\hline $\begin{array}{l}\text { Triceps skinfold } \\
\text { thickness }(\mathrm{mm})\end{array}$ & \multicolumn{2}{|c|}{$23.2 \pm 3.1$} & \multicolumn{2}{|c|}{$20.1 \pm 2.16$} & \multicolumn{2}{|c|}{$20.0 \pm 5.4$} & \multicolumn{2}{|c|}{$18.7 \pm 2.5$} & \multicolumn{2}{|c|}{$18.7 \pm 5.2$} & \multicolumn{2}{|c|}{$16.7 \pm 2.5$} & $0.01 *$ \\
\hline $\begin{array}{l}\text { Mid arm } \\
\text { circumference }(\mathrm{cm})\end{array}$ & \multicolumn{2}{|c|}{$15.6 \pm 5$} & \multicolumn{2}{|c|}{$12.4 \pm 1.9$} & \multicolumn{2}{|c|}{$17.5 \pm 8.2$} & \multicolumn{2}{|c|}{$17.5 \pm 10.6$} & \multicolumn{2}{|c|}{$15.6 \pm 5$} & \multicolumn{2}{|c|}{$11.1 \pm 2.2$} & $0.023 *$ \\
\hline Weight & \multicolumn{2}{|c|}{$61.6 \pm 15.2$} & \multicolumn{2}{|c|}{$62.4 \pm 11$} & \multicolumn{2}{|c|}{$66.6 \pm 3.6$} & \multicolumn{2}{|c|}{$73.4 \pm 12.7$} & \multicolumn{2}{|c|}{$66.4 \pm 7.4$} & \multicolumn{2}{|c|}{$59.3 \pm 14.4$} & $0.012 *$ \\
\hline Skin turgor: & No & $\%$ & No & $\%$ & No & $\%$ & No & $\%$ & No & $\%$ & No & $\%$ & \multirow[t]{3}{*}{$0.01 *$} \\
\hline Normal-moist & 12 & 40 & 17 & 53.7 & 22 & 73.4 & 17 & 53.7 & 15 & 50 & 12 & 40 & \\
\hline Dry skin & 18 & 60 & 13 & 46.3 & 8 & 26.6 & 13 & 46.3 & 15 & 50 & 18 & 60 & \\
\hline Mucous membrane: & No & $\%$ & No & $\%$ & No & $\%$ & No & $\%$ & No & $\%$ & No & $\%$ & \multirow{4}{*}{0.067} \\
\hline Normal (pink - intact) & 9 & 30 & 12 & 40 & 20 & 66.6 & 18 & 60 & 7 & 23.3 & 9 & 30 & \\
\hline Pale & 18 & 60 & 15 & 50 & 8 & 26.7 & 8 & 26.6 & 18 & 60 & 16 & 53.3 & \\
\hline Cyanosed & 3 & 10 & 3 & 10 & 2 & 6.6 & 4 & 13.4 & 5 & 16.7 & 5 & 16.7 & \\
\hline
\end{tabular}

Independent samples t-test $\quad * \mathrm{P}<0.05$ significant

Table (6): it showed highly statistical significantly difference in nutritional assessment parameters in study group which reflect nearly normal skin turgor, Triceps skinfold thickness \& Mid arm circumference) $\mathrm{P}<0.01$ by the end of the study but in control group showed slightly decreased than normal it was test $\mathrm{P}>0.05$ while no statistical significantly difference was founded in both groups in Weight and Mucous membrane assessment .

Table (7): comparison between both study \& control group regard to patients' hemodynamic monitoring parameters:

\begin{tabular}{|c|c|c|c|c|c|c|c|}
\hline \multirow{3}{*}{ Items } & \multicolumn{6}{|l|}{ Groups } & \multirow{3}{*}{$\begin{array}{l}\mathrm{P}- \\
\text { value }\end{array}$} \\
\hline & \multicolumn{3}{|c|}{ Study $(n=30)$} & \multicolumn{3}{|c|}{ Control $(n=30)$} & \\
\hline & $1^{\text {st }}$ day & $3^{\text {rd }}$ day & $7^{\text {th }}$ day & $1^{\text {st }}$ day & $3^{\text {rd }}$ day & $7^{\text {th }}$ day & \\
\hline Heart rate & $90.0 \pm 23.5$ & $99.1 \pm 27.0$ & $92.0 \pm 18.0$ & $103.9 \pm 20.8$ & $101.7 \pm 18.5$ & $101.5 \pm 16.8$ & $0.01 *$ \\
\hline $\begin{array}{l}\text { Systolic blood } \\
\text { pressure }\end{array}$ & $135.0 \pm 27.0$ & $128.0 \pm 22.1$ & $133.0 \pm 15.7$ & $29.0 \pm 22.0$ & $132.6 \pm 17.0$ & $130.0 \pm 10.8$ & 0.35 \\
\hline $\begin{array}{l}\text { Diastolic blood } \\
\text { pressure }\end{array}$ & $67.9 \pm 28.5$ & $78.0 \pm 20.7$ & $81.0 \pm 13.9$ & $72.3 \pm 25.9$ & $81.3 \pm 13.5$ & $80.6 \pm 11.1$ & 0.534 \\
\hline $\begin{array}{l}\text { Mean arterial } \\
\text { pressure }\end{array}$ & $89.0 \pm 17.2$ & $86.5 \pm 12.8$ & $88.5 \pm 12.8$ & $88.4 \pm 20.3$ & $93.0 \pm 9.5$ & $94.5 \pm 14.3$ & $0.01 *$ \\
\hline Temperature & $37.3 \pm 0.5$ & $37.7 \pm 0.9$ & $39.1 \pm 2.9$ & $37.3 \pm 0.4$ & $37.6 \pm 0.6$ & $38.0 \pm 3.5$ & 0.69 \\
\hline CVP reading & $12.4 \pm 3.0$ & $11.6 \pm 3.4$ & $11.1 \pm 4.3$ & $10.4 \pm 3.7$ & $10.8 \pm 3.2$ & $22.0 \pm 3.5$ & $0.01 *$ \\
\hline SPO2 & $95.2 \pm 7.9$ & $95.2 \pm 3.1$ & $94.8 \pm 3.9$ & $99.2 \pm 7.3$ & $95.8 \pm 2.3$ & $89.8 \pm 18.5$ & 0.157 \\
\hline
\end{tabular}

Chi-square test $* \mathrm{P}<0.05$ significant

Table (7): it show statistical significantly difference between study \& control group in pulse rate, mean arterial blood pressure while CVP readings show increase than normal in control group at 7 th day compared to study group. No statistical significantly difference founded in blood pressure and oxygen saturation

Table (8): comparison between both study \& control group regard to TPN complications:

\begin{tabular}{|c|c|c|c|c|c|c|c|c|c|c|c|c|c|}
\hline \multirow{4}{*}{ Items } & \multicolumn{12}{|c|}{ Groups } & \multirow{4}{*}{ P-value } \\
\hline & \multicolumn{6}{|c|}{ Study $(n=30)$} & \multicolumn{6}{|c|}{ Control $(n=30)$} & \\
\hline & \multicolumn{2}{|c|}{$1^{\text {st }}$ day } & \multicolumn{2}{|c|}{$3^{\text {rd day }}$} & \multicolumn{2}{|c|}{$7^{\text {th }}$ day } & \multicolumn{2}{|c|}{$1^{\text {st }}$ day } & \multicolumn{2}{|c|}{$3^{\text {rd }}$ day } & \multicolumn{2}{|c|}{$7^{\text {th }}$ day } & \\
\hline & No & $\%$ & No & $\%$ & No & $\%$ & No & $\%$ & No & $\%$ & No & $\%$ & \\
\hline $\begin{array}{l}\text { Hyperglycaemia } \\
\text { blood sugar }>80\end{array}$ & 12 & 40 & 3 & 10 & 1 & 3 & 9 & 30 & 7 & 23 & 13 & 43 & $0.01 *$ \\
\hline $\begin{array}{l}\text { Hypoglycaemia } \\
\text { blood sugar }<80\end{array}$ & 12 & 40 & 6 & 20 & 9 & 30 & 4 & 13 & 5 & 17 & 3 & 10 & $0.019 *$ \\
\hline $\begin{array}{l}\text { Hyponatremia } \\
\mathrm{Na}<135\end{array}$ & 6 & 20 & 3 & 10 & 3 & 10 & 8 & 27 & 1 & 3 & 12 & 40 & $0.09 *$ \\
\hline $\begin{array}{l}\text { Hypokalemia } \\
\mathrm{K}<3 \mathrm{mmol} / \mathrm{l}\end{array}$ & 3 & 10 & 3 & 10 & 3 & 10 & 0 & 0 & 4 & 13 & 13 & 43 & $0.01 *$ \\
\hline Hypomagnesemia & 3 & 10 & 1 & 3 & 0 & 0 & 3 & 10 & 4 & 13 & 6 & 20 & $0.009 *$ \\
\hline
\end{tabular}

Chi-square test $\mathrm{P}>0.05$ non-significant

Table (8) illustrated that there were decrease in the percentage of patient's had Hyperglycemia in the $7^{\text {th }}$ day than $1^{\text {st }}$ and $3^{\text {rd }}$ day for study group compared to control group .more over there were a ssignificant difference for 
serum sodium , potassium and magnesium level in the $7^{\text {th }}$ day than $1^{\text {st }}$ and $3^{\text {rd }}$ day for study group compared to control group $\mathrm{P}<0.05$ respectively

Table (9): comparison among studied groups regarding patients' outcome

\begin{tabular}{|c|c|c|c|c|c|}
\hline \multirow{3}{*}{ Items } & \multirow{2}{*}{\multicolumn{2}{|c|}{ Study $(n=30)$}} & \multicolumn{2}{|c|}{ Groups } & \multirow[t]{3}{*}{ P-value } \\
\hline & & & \multicolumn{2}{|c|}{ Control $(n=30)$} & \\
\hline & No & $\%$ & No & $\%$ & \\
\hline $\begin{array}{l}\text { Weight loss } \\
\text { yes } \\
\text { No }\end{array}$ & $\begin{array}{l}6 \\
24\end{array}$ & $\begin{array}{l}20.0 \\
80.0\end{array}$ & $\begin{array}{l}11 \\
19\end{array}$ & $\begin{array}{l}36.7 \\
63.7\end{array}$ & $0.023 *$ \\
\hline $\begin{array}{l}\text { Serum protein decreased } \\
\text { yes } \\
\text { No }\end{array}$ & $\begin{array}{l}3 \\
27\end{array}$ & $\begin{array}{l}10 \\
90\end{array}$ & $\begin{array}{l}4 \\
26\end{array}$ & $\begin{array}{l}13.3 \\
86.7\end{array}$ & 0.251 \\
\hline $\begin{array}{l}\text { Positive nitrogen balance } \\
\text { yes } \\
\text { No }\end{array}$ & $\begin{array}{l}27 \\
3\end{array}$ & $\begin{array}{l}90 \\
10\end{array}$ & $\begin{array}{l}20 \\
10\end{array}$ & $\begin{array}{l}66.7 \\
33.3\end{array}$ & $0.001 * *$ \\
\hline $\begin{array}{l}\text { Fluid balance } \\
\text { yes } \\
\text { No }\end{array}$ & $\begin{array}{l}20 \\
10\end{array}$ & $\begin{array}{l}66.7 \\
33.3\end{array}$ & $\begin{array}{l}11 \\
19\end{array}$ & $\begin{array}{l}36.7 \\
63.7\end{array}$ & $0.023 *$ \\
\hline Mortality rate & 3 & 10 & 4 & 13.3 & 0.69 \\
\hline \multirow[t]{2}{*}{ Mechanical complications occurs } & 3 & 10 & 4 & 13.3 & 0.25 \\
\hline & \multicolumn{2}{|c|}{ Mean \pm SD } & \multicolumn{2}{|c|}{ Mean \pm SD } & \\
\hline Length of ICU stay & \multicolumn{2}{|c|}{$13 \pm 6.16$} & \multicolumn{2}{|c|}{$17.2 \pm 6.16$} & $0.04 *$ \\
\hline No of days patient on mechanical ventilator & \multicolumn{2}{|c|}{$10 \pm 4.7$} & \multicolumn{2}{|c|}{$11 \pm 6.7$} & 0.92 \\
\hline
\end{tabular}

Chi-square test $\quad * \mathrm{P}<0.05$ significant

Table (9) Show that for patient outcomes the highest percentage were ( $80 \%$ ) for study group had no weight loss and within normal serum protein (90\%) compared to ( 63.3 and $86.7 \%)$ in control group respectively .Regarding to study sample had positive nitrogen and fluid balance the percentage was ( 90 and 66.7 ) compared to 66.7 and 36.7) for control group . in addition to moderate statistical difference in length of ICU stay in study group compared to control group

\section{Discussion}

Critically ill patient has increase in metabolism rate, loss of lean body mass and require greater energy. Nutritional support is a critical need for ICU patients to improve clinical outcomes, so it is very important to select proper patient, timing and route of administration of nutrient and monitoring of the therapy (Pichard et al; 2009).TPN is mostly indicated when enteral or oral routes cannot provide adequate nutrients to patients but associated with several complications. (Omar ,2014 \& Kheir; 2014)

Total Parenteral Nutrition(TPN)is used for patients who have nonfunctional gastrointestinal tracts(GITs) and are un able to take meals by other routes.TPN provides nutrients such as glucose, amino acids, lipids and added vitamins and dietary minerals which are essential elements for the survival of a person .TPN is mostly used for the patients who are admitted to the critical care units owing to the dependent nature of their diseases. Thomas,2010\&. Jie etal , 2012 concluded that significantly improvements in clinical outcome founded in nutritional support group that meets guideline standards .Mault J, 2010 reported that acute illness lead to poor nutritional status by increasing metabolic rate and impairing their utilization of nutritional substrates.

The current study found that no statistically significant differences were founded in demographic and clinical data between both study and control group .Altintas et al. ,2011 In line with our results, and concluded that there was no difference between groups as regards age, sex.Moreover Nagata et al.,2011 Also found the similar results when they studied enteral and complementary parenteral nutritional support methods. As regards the daily caloric and protein requirements no statistical significant difference among the studied patients

Hamaoui et al.;2014 compare enteral nutrition versus total parenteral nutrition and found that no statistical significant difference in relation to daily requirements. .Krishnan et al, 2013) concluded that calculation of both energy and protein requirements must be assessed on admission to the intensive care unit to determine accurate nutrition therapy .In addition to (Sungurtekin et al., 2008 \& Jagoe et al.,2008) who add that malnutrition is a common problem in hospitalized patients. More than $1 \backslash 3$ intensive care unit patients diagnosed as malnourished when admitted to the ICU which lead to increased infection risk, development of pressure ulcers, delay wound healing and prolonged hospital stays and increase mortality rate (Martin et al.,2004).

Improvement of patients' respiratory system assessment at the 7th day compared to the $1 \mathrm{st}$ and $3 \mathrm{rd}$ day of study group compared to control group. Kudsk, etal, 2014 concluded that, the incidence of respiratory infection in the TPN group was sigficant. Also Kalfarentzos ,2014 reported that infections were higher in the TPN group 
than in the EN group

Braunschweig et al, 2012 discussed that infection associated with parenteral nutrition are explained by many reasons as hyperglycemia which reduce neutrophil chemotaxis and phagocytosis .M. Sharada ,2014 reported that ICU patients always suffer from weakness of respiratory muscles This usually lead to prolonged mechanical ventilation, difficult weaning and infections and even death

Sun ,2016 founded that the incidence of infectious complications was lower among patients who received guideline standards lower than that in patients who did not meet guideline standards .The current study showed that there was no statistically significant difference in the number of patients on MV among both groups and that the duration of MV was higher in the control group in addition the difference was statistically non significant .Gramlich et al. ,2008 agreed the results and found no statistical significant difference in total parenteral nutrition groups regarding duration of mechanical ventilation.

In our study there are significantly difference regard to the mean values of WBC, red blood cells, Hematocrit and blood urea nitrogen $<0.05$ Whil there were moderate statistical difference for hemoglobin concentration $<0.01$ founded by the end of the study between 2 groups . Regarding to kidney function it showed that statistical difference in the $7^{\text {th }}$ day in most of parameters in study group except blood sugar level which decreased in $7^{\text {th }}$ day compared to $1^{\text {st }} \& 3^{\text {rd }}$ day while in control group it show abnormal decrease in serum sodium, potassium, Magnesium and also show abnormal increases in serum blood urea nitrogen, blood sugar

During the period of the study, the mean value of albumin level $(\mathrm{g} / \mathrm{dl})$ did not show. statistically significant difference in its level among the both group at 1 st day, $3^{\text {rd }}$ day and $7^{\text {th }}$ day (respectively ). The similarity founded with Huang et al. ;2015 who concluded that, no statistically significant differences were found in total proteins and albumin levels at the 1stand 7th days. And Daneshzad et al,2015 who reported that Serum albumin level was less than normal range in about $60 \%$ of patients in the first day of staying in ICU then increased to $77 \%$ in the seventh day of hospitalization.

Shenkin , 2006 reported that the vital role of nurse for patient receiving nutritional support are assessment of electrolytes as calcium, magnesium, glucose level, sodium and potassium, Monitor blood glucose level /laboratory values and inform physician of abnormalities during TPN administration, assess skin turgor, weight, assess vital signs and auscultate lungs.

The current study showed highly statistical significantly difference in nutritional assessment parameters in study group which reflect nearly normal skin turgor, Triceps skinfold thickness \& Mid arm circumference) $\mathrm{P}<0.01$ by the end of the study but in control group showed slightly decreased than normal it was test $\mathrm{P}>0.05$ while no statistical significantly difference was founded in both groups in Weight and Mucous membrane assessment .Martin et al ;2004 concluded that anthropometric measures, electrolytes , skinfold thickness , midarm circumference should be done twice-upon admission and 7 days after admission

Daneshzad E etal ,2015 founded There was a significant reduction in the mean of mid arm circumference after 1 week staying in ICU . Also Sungurtekin et al.,2008 who shown A reduction in anthropometric measurements in patients staying in the ICU .Lee \&Neiman ,2007 reported the triceps and subscapular skinfolds are the most useful for nutritional evaluationin the acute care setting. Hejazi $\mathrm{N}$ et al,2016 founded that significantly increased on the day of discharge compared to the day of admission in relation to patients' weight, mid-upper-arm circumference, mid-arm muscle circumference, triceps skinfold thickness and biochemical indices showed no notable changes except for magnesium, which decreased significantly

Our study show that there were decrease in the percentage of patient's had Hyperglycemia in the $7^{\text {th }}$ day than $1^{\text {st }}$ and $3^{\text {rd }}$ day for study group compared to control group .more over there were a significant difference for serum sodium , potassium and magnesium level in the $7^{\text {th }}$ day than $1^{\text {st }}$ and $3^{\text {rd }}$ day for study group compared to control group $\mathrm{P}<0.05$ respectively

Meirelles' \& Nascimento ,2011 found that serum glucose progressively increased in the two groups but hyperglycemia the most frequent metabolic complication in the TPN was significantly. Braunschweig et al. ,2012 reviewed many researches that reported metabolic complications as hyperglycemia in TPN and found that hyperglycemia was accompany by stress response result in more endogenous glucose production and insulin resistance

The results of this study showed that hypokalemia and hypophosphatemia were higher in the control group versus study group .These results can be explained by hyperglycemia that usually present during TPN, the movement of glucose into the cells is usually associated with an intracellular shift of potassium and phosphate .In agreement with this result Abd El Rahim , 2015 founded that $>20 \%$ in both group had hypokalemia and hypophosphatemia were higher in the TPN group .Paolo Cotogni ,2017 said that metabolic complications are common in critically ill patients as altered hydration status, electrolyte disturbances, and hyperglycemia so clinical - and laboratory investigation is very important To decrease edema and fluid retention

Banh ,2010 A. prins ;2010 illustrated that amino acids and protein element in patients admitted to ICU is affected by many factors; such as hydration status, therapeutic administration of albumin, hepatic and renal function and the patient response in acute phase. Ferrie \&. Daniells; 2011 reported that nitrogen balance 
assessment is the only biochemical parameter that truly reflects visceral and somatic protein pools and nitrogen balance is the most accurate measurement of protein status, by comparing nitrogen output and input. Positive nitrogen balance indicates anabolism. Negative nitrogen balance indicates catabolism.

Zaloga , 2011 concluded that Nutritional support plays a vital role in the prevention nutritional deficiencies in ICU patients, improved outcomes, lower infection rates, and reduced hospital lengths of stay \& helps complications prevention.Zaloga and marit, 2013 mentioned that sodium, potassium, blood glucose, blood urea nitrogen, phosphorus, magnesium Notify the physician Signs and symptoms of CVC infection, lipid intolerance as fever, chills, vomiting, urticaria, chest/back pain and Signs and symptoms of rapid infusion reaction to lipids: palpitations, tachypnea, wheezing, cyanosis, nausea, pain at injection site, headache, oily taste in mouth and Signs and symptoms of fluid volume overload or dehydration.

As regards the length of hospital stay it was higher in the control group and the difference was statistically significant study .In agreement with our result, Huang et al.;2015found that the hospital stay in the TPN groupwas statistically significant longer than in EN group

Shum , 2011 reported Body weight fluctuates daily throughout a patient's stay in the intensive care unit (ICU) due to a variety of factors, including fluid balance, nutritional status

Alsous ,2010 mentioned that fluid balance estimation is critical for assessing the fluid status as well as metabolic status of critically ill patients compared to traditional means of assessment. Jie , 2012 Saied total parental nutrition (TPN) is adminisred for at least seven days to improve clinical outcomes TPN for $\geq 7$ days significantly reduce the rate of infectious complications compared with no nutritional support at all

Simmons et al ,2014 reported that patients who gained weight did not survive more than those who lost their weight In a short-term period. Fluid overload mainly influences on gaining body weight over fluid administration reflects severity in critically ill patients. Shum , 2013 Weight gain on days 3 through 7 was correlated with the prolonged use of mechanical ventilation and increase in body weight on days 2 through 7 related to longer stay of ICU. Weight gain on days 3,4, and 5 was associated with increased ICU mortality. Our results suggests short term weight gain may have a negative influence on clinical outcome in the critically ill patients

Heyland , 2012 The advantages of parenteral nutrition support in the critically ill include enhanced wound healing, a decreased catabolic response to injury and improved clinical outcomes including a reduction length of stay with accompanying cost savings. However, nutrition support is not without adverse effects or risks. Robinson etal , 2010 Dempsey ; 2011 Critically ill patients frequently receive inadequate nutritional support during their ICU stay because physicians underestimate the nutritional needs of patients, and ICU stay due to increased ventilator dependency, higher rates of infection, and impaired wound healing.

Heyland ,2016 Parenteral nutrition has been associated with gut mucosal complications, metabolic complications, an increased risk of infectious and increased mortality in critically ill patients. Don\& Kaysen , 2004 nitrogen balance reflects serum protein stores. Nitrogen is a major product of protein catabolism; its rate of urinary excretion can be used to assess protein adequacy. The amount of nitrogen excreted in the urine is typically measured as the 24-hour urinary urea nitrogen (UUN). If there is a positive urinary nitrogen balance, protein metabolizing is sufficient, and nitrogen is excreted in the urine.

Our detailed assessment of the patients in the ICU indicated that mean weight, and calf circumference decreased significantly during their ICU stay. These findings are in agreement with those reported by Nematy et al. ;2012 who showed a significant decrease in weight and TSF among their patients in the ICU

In the current study, a significant drop in lean mass weight and body cell mass was detected in the patients on the day of discharge, while no significant change was observed in the patients' fat mass. A declining trend in the patients' dry lean mass was also seen during their ICU stay. These findings are consistent with those reported by Fuentes et al. ,2010, who demonstrated a decrease in their patients' muscle mass and an increase in fat mass during the first 7days after ICU admission. A possible explanation for the drop in patients' lean body mass during their ICU stay may be, in part, an increase in inflammation since it helps accelerate the degradation of muscle proteins Immobilization is another important discharge day and the mean caloric intake after controlling for the length of ICU stay, inadequate intake was notable due to clinical reasons. Inadequate intakes of energy

By comparing biochemical data and anthropometric measurements, the present study showed that anthropometric measurements were a better predictor of the nutritional outcome (severity of malnutrition) of critically ill patients. In this regard, Sungurtekin et al, 2008 revealed a reverse significant relationship between anthropometric measurements and biochemical data on the admission day of their patients to the ICU. In contrast to our study, however, the authors reported a significant correlation between albumin level and SGA. The peculiarities of albumin metabolism affect the interest in that for assessing nutritional status in critically ill patients.40 Thus, anthropometric measurements constitute a noninvasive, cost-effective, and rapid way to evaluate the nutritional status of patients in the ICU.

\section{6- Conclusion and Recommendations:}

Based on the findings of the present study, TPN nursing guidelines improve patient's clinical outcomes and reduce 
occurrence of complications.

In the light of the above, the following recommendations are suggested:

-Establishing a standardized intervention for TPN administration.

-Equip the critical care units by the recent infusion pump and other technology to optimizing nursing care.

Update the critical care nurses knowledge about TPN guidelines

- Presence and reviewing of patient`s records for proper follow up.

\section{7-References}

1. A prins (2016): Nutritional assessment of the critically ill patient, J. Clin. Nutr. 23 (1) 11-18.

2. Abd El Rahim I, El Gabry M, El-Shabrawy M, and Mohammed R (2017): Assessment of nutritional support in critically ill patients and its correlation with outcomes at respiratory intensive care unit Egyptian Journal of Chest Diseases and Tuberculosis 66, 251-260

3. Shenkin A:(2006 )Biochemical monitoring of nutrition support The Association for Clinical BiochemistryReview Article

4. Alsous F, Khamiees M, and DeGirolamo A,. (2010) :Negative fluid balance predicts survival in patients with septic shock: a retrospective pilot study. Chest;117:1749-54.

5. Altintas, K, Aydin M,and Turkogl U: (2011) Effect of enteral versus parenteral nutrition on outcome of medical patients requiring mechanical ventilation, Nutr. Clin. Pract. 26 (3) 322-329.

6. American Association of Critical-Care Nurses (AACN). (2015). About critical care nurses. AACN. Retrieved fromhttp://www.aacn.org/wd/publishing/content/pressroom/aboutcriticalcarenursing.pcms?menu

7. Banh (2010): Serum proteins as a marker of nutrition: what are we treating?, Pract Gastroenterol. 10 46-64

8. Braunsch P (2012): Timing and route of nutritional support. Nutrition and critical care: Nestle' Nutrition Workshop Series Clinical \& Performance Program. Basel, Switzerland: Karger,; 297-330

9. Braunschweig, P and Levy .M.(2012): Enteral compared with parenteral nutrition: a meta-analysis, Am. J. Clin. Nutr. 74 534-542.

10. Morton P and Fontaine D.(2015):Critical care nursing, Aholistic approach. $8^{\text {th }}$ ed p:313-315

11. Morton $P$ and Fontaine D.(2018):Critical care nursing, Aholistic approach. $8^{\text {th }}$ ed p:313-315.

12. Sun W, Ming L, and Shu Y (2016) : Impact of nutritional support that does and does not meet guideline standards on clinical outcome in surgical patients at nutritional risk: a prospective cohort study Sun et al. Nutrition Journal 15:78

13. Daneshzad E, Azadbakhat L, Neamani F, Abasi S, Shirani F, Adibi P. Huang, Z. Sun, J. and Huang, A (2015) : Early enteral nutrition in combination with parenteral nutrition in elderly patients after surgery due to gastrointestinal cancer, Int. J. Clin. Exp. Med. 8 (8) 13937-13945

14. Don R, and Kaysen G. (2004) :Serum albumin: relationship to inflammation and nutrition. Semin Dial; 17(6):432-437.

15. Dudek, S.(2016):Nutrition Essentials for Nursing Practice (5th Edition). eBook available via the University of Toronto Library at http://ovidsp.tx.ovid.com.myaccess.library.utoronto.ca/spb/ovidweb.cgi

16. Ferreira, P (2017): Total parenteral nutrition. Powerpoint presentation available at North York General Hospital at www.nygh.on.ca

17. Ferrie S, Daniells S, and Gagnon A (2011): Enteral Nutrition Manual for Adults in Health Care Facilities, Dietitians Association of Australia, , pp. 1-49

18. Fuentes T, Miranda C, Diaz J, Muniz V, Estalella G, Corral M. (2010 ):Assessment of changes in body composition in critically ill patients. Enferm Intensiva.;21:113-9.

19. Gramlich, $\mathrm{K}$ and Kichian, J(2008): Does enteral nutrition compared to parenteral nutrition result in better outcomes in critically ill adult patients? A systematic review of the literature, Nutrition 20 843-848. GrawHill; p,p270-285 .

20. Grenvick A, Ayres S, and Holbrook P, (2014) :Textbook of critical care. nutrition in the critically ill patient 4th ed. Philadelphia, PA: WB Saunders, ; 875-89

21. Gonce P,Fontaine D.(2018):critical care nusing -Holistic approach .12ed .Wolkers Kluwer/Lippincott Williams \&Wilkin.printed in china

22. Gonce P,Fontaine D.(2016):critical care nusing -Holistic approach .12ed .Wolkers Kluwer/Lippincott Williams \&Wilkin.printed in china

23. Hamaoui, R. Lefkowitz, L. Olender, L(2014): Enteral nutrition in the early postoperative period: a new semielemental formula versus total parenteral nutrition, JPEN J. Parent. Enteral Nutr. 14 (5) 501-507

24. Hejazi N, Mazloom Z, Zand F, Rezaianzadeh A, Amini A. (2016) :Nutritional Assessment in Critically Ill Patients . Iran J Med Sci.;41(3):171-179.

25. Heyland D, and MacDonald S, and Keefe L (2016) : Total parenteral nutrition in the critically ill patient; A meta-analysis. JAMA. Dec 16;280(23):2013-9. 
26. Heyland K. (2012) Nutritional support in the critically ill patient, a critical review of the evidence. Crit Care Clin. Jul;14(3):423-40.

27. Huang, Z and Sun, J. (2015): Early enteral nutrition in combination with parenteral nutrition in elderly patients after surgery due to gastrointestinal cancer, Int. J. Clin. Exp. Med. 8 (8) 13937-13945

28. Huang, Z. Sun, J. and Huang (2015): Early enteral nutrition in combination with parenteral nutrition in elderly patients after surgery due to gastrointestinal cancer, Int. J. Clin. Exp. Med. 8 (8) 13937-1394

29. Jagoe R, Goodship T, and Gibson G (2008): The influence of nutritional status on complications after surgery for lung cancer. Ann Thorac Surg;71:936- 43.

30. Jie B, Jiang M, Nolan T(2012) :Impact of preoperative nutritional support on clinical outcome in abdominal surgical patients at nutritional risk. Nutrition.;28:1022-7

31. Kalfarentzos, J. and Kehagias,E (2012): Enteral nutrition is superior to parenteral nutrition in severe acute pancreatitis: results of a randomized prospective trial, Br. J. Surg. 84 1665-1669

32. Kheir S. All rights are reserved Citation: Assasa O and Kheir F. (2014): Nutrition in Critically Ill Patients. Austin Crit Care J.;1(1): 2.

33. Krishnan J, Parce P, Martinez A, Diette B, and Brower G. (2013) Caloric intake in medical ICU patients: consistency of care with guidelines and relationship to clinical outcomes. Chest;124(1):297-305.

34. Kudsk, M. Croce, T. and Fabian, (2014) :Enteral versus parenteral feeding. Effects on septic morbidity after blunt and penetrating abdominal trauma, Ann. Surg. 215 -503-511.

35. Lee R, and Neiman D.( 2007 ): Nutritional assessment, 4th ed. Boston: Mc-

36. Msharada, M. and Vadivelan D (2014) : Nutrition in critically ill patients, JIACM 15 (3-4) 205-209.

37. Martin M, Doig S, Heyland K, Morrison T, and Sibbald J.( 2004) :Multicentre, cluster-randomized clinical trial of algorithms for critical-care enteral and parenteral therapy . Can Med Assoc J;170(2):197-204.

38. Mault J,(2010) :ICU Nutritional Study Group. Energy balance and outcome in critically ill patients: results of a multi-center, prospective, randomized trial. Scientific Abstracts

39. Meirelles ,and Nasciment O (2011) : Enteral or parenteral nutrition in traumatic brain injury: a prospective randomized trial, Nutr. Hosp. 26 (5) 1120-1124.

40. Nagata, K. Fukuzawa, Y. and Iwashit A (2011): Comparison of enteral nutrition with combined enteral and parenteral nutrition in post pancreaticoduodenectomy patients: a pilot study, Nutr. J. 824.

41. Nematy M, Mohajeri R, Moghadam A, Safarian M, Norouzy A, and Parizadeh S,( 2012): Nutritional status in intensive care unit patients: a prospective clinical cohort pilot study. Med J Nutrition Metab.;5:163-8.

42. Omar A and Fayez K (2014 ): Nutrition in Critically Ill Patients Austin Crit Care J - Volume 1 Issue 1 www.austinpublishinggroup.com

43. Pmarino (2014 ): Nutritional Requirements in Marino P L; The ICU Book, fourth ed., Lippincott Williams \& Wilkins, pp. 799-807.

44. Paolo C (2017): Management of parenteral nutrition in critically ill patientsWorld J Crit Care Med February 4; 6(1): 13-20

45. Perry, A.and Potter P . (2016): Clinical Nursing Skills and techniques 6th edition. Philadelphia: Elsevier Mosby

46. Pichard, R. Thibault, C.and . Heidegge R, (2009): Enteral and parenteral nutrition for critically ill patients: a logical combination to optimize nutritional support, Clin. Nutr. Suppl. 4 (1) 3-7.

47. Plumer S (2017): Principles \& Practice of Intravenous Therapy, Eighth ed. Philadelphia: Lippincott Williams \& Wilkins; p. Ch 16. P361-411

48. Robinson G, Goldstein M, and Levine G (2010): Impact of nutritional status on DRG length of stay. JPEN J Parenter Enteral Nutr; 11:49-51

49. Shum P, Lee M, and Chan C( 2011) Interaction between fluid balance and disease severity on patient outcome in the critically ill. J Crit Care 26:613-9.

50. Shum H, Lee M, and Chan C (2013): Interaction between fluid balance and disease severity on patient outcome in the critically ill. J Crit Care 26:613-9.

51. Simmons R, Berdine G, and Seidenfeld J, (2014) Fluid balance and the adult respiratory distress syndrome. Am Rev Respir Dis;135:924-9

52. Smith- J. and Young J. (2015): Nurses' Guide to Clinical Procedures eBook available via the University of Toronto Library at http://ovidsp.tx.ovid.com.myaccess.library.utoronto.ca/spb/ovidweb.cg

53. Sungurtekin K, Sungurtekin U, Oner O, and Okke D.(2008) :Nutrition assessment in critically ill patients. Nutr Clin Pract;23(6):635- 41.

54. Thomas,R..(2010):Totalparenteralnutrition.U.S.NationalLibraryofMedicine,NationalInstitutesofHealth. Retrieved fromhttp:/www.nlm.nih.gov/medlineplus/druginfo/meds/a601166.html

55. Zaloga G,and Marik P (2013):Feeding the Hemodynamically Unstable Patient: A Critical Evaluation of the Evidence. Nutrition in Clinical Practice.;18(4):285-293. 